\title{
The FGM/C research programme
}

Jacinta Muteshi-Strachan

Population Council

Follow this and additional works at: https://knowledgecommons.popcouncil.org/departments_sbsr-rh

Part of the Demography, Population, and Ecology Commons, Family, Life Course, and Society Commons, International Public Health Commons, Maternal and Child Health Commons, Sociology of Culture Commons, and the Women's Health Commons How does access to this work benefit you? Let us know!

\section{Recommended Citation}

Muteshi-Strachan, Jacinta. 2016. "The FGM/C research programme," presentation at the International Conference to End FGM, Geneva, 10-11 May. Nairobi: Population Council. 


\title{
Evidence to End FGM/C (
}

\section{The FGM/C Research Programme}

\author{
Jacinta Muteshi; Ph.D. \\ Population Council
}

Inter-African Committee (IAC)

International Conference to end FGM

Geneva, Switzerland: 10-11 May, 2016 


\section{Why a research programme on FGM/C}

$\checkmark$ Intensive Africa-led advocacy in the past decade has led to widespread agreement on the need for intensifying efforts to end FGM/C within one generation

$\checkmark$ Historically low levels of funding for FGM/C research has led to a global evidence base suffering from many critical gaps

$\checkmark$ Global and national efforts to end FGM/C rapidly can be more effective and efficient when informed by high quality evidence generated through rigorous, ethical and appropriate research 


\section{Our goal for 2020}

DFID's Programme 'Towards Ending FGM/C in Africa and Beyond'

3 components

- Population Council

- UNFPA-UNICEF Joint Programme on FGM/C: accelerating change

- The Girl Generation

Duration: 2016 - February 2020

\section{Contribute to Impact}

End to the practice in one generation and a reduction in the practice by $30 \%$ in at least ten countries within five years

\section{Research Goal}

Generate evidence to influence strategic investments, policies, and programs to end $\mathrm{FGM} / \mathrm{C}$ 


\section{Geographic focus: 7 countries}

\section{Criteria}

Scale of the practice: Six countries with combined population of over 90 million girls and women who have been cut, $70 \%$ of total

Represent all 5 stages of transition in abandonment

Socio-cultural variations

UNJP and TGG programming and intervention priority countries

VfM through cost-effective programme implementation: Experienced research teams available in all six countries; Consortium managed within the region; Partners able to work in Anglophone, Francophone and Arabic contexts

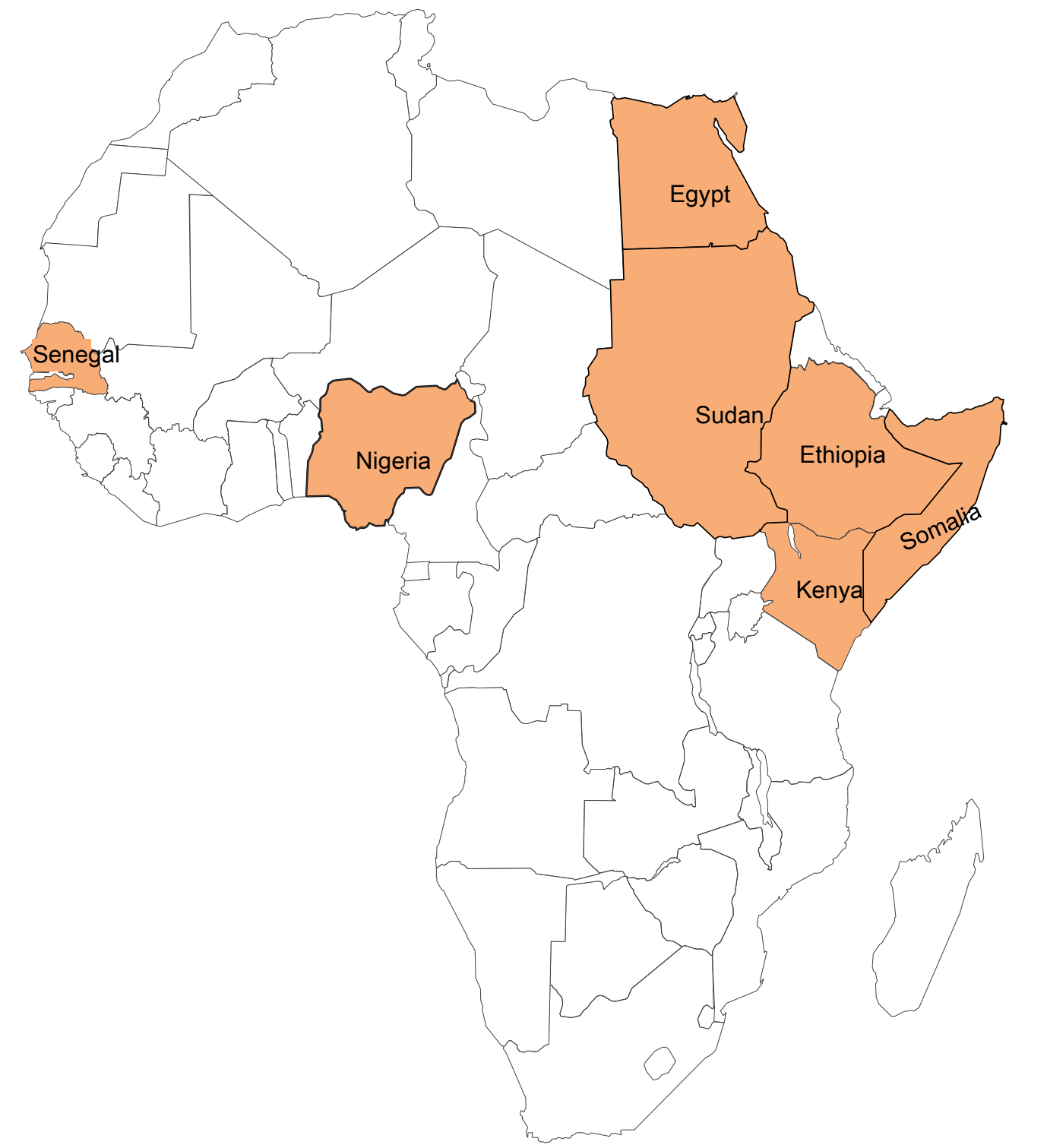




\section{The FGM/C Research Programme Our Consortium}

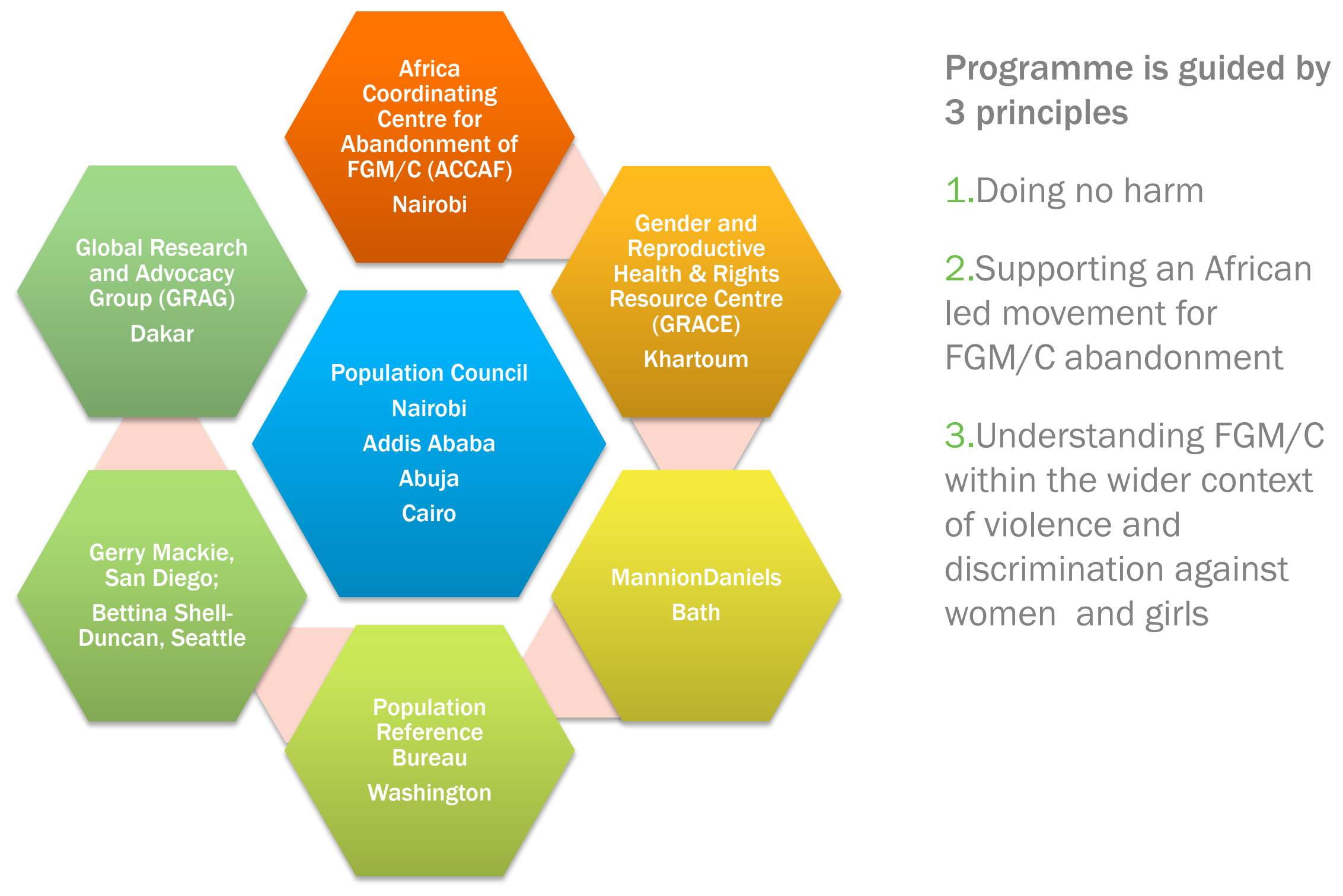




\section{Our Research Goal}

- Expanded global evidence base on FGM/C influences decisionmaking for strategic investment, policy and programming to end FGM/C 


\section{Four research}

\section{themes}




\section{Study method}

\section{Countries}

of key evidence: measurement challenges

3 Desk-based literature reviews and syntheses

i. Synthesis and translation of existing evidence for new strategies to test for FGM/C abandonment

ii. Compendium of ongoing and recently completed FGM/C interventions to inform future designs

iii. Synthesised evidence on FGM/C health impacts in formats appropriate for strengthening training of mid-level health workers

Synthesis of key evidence issues and

$\square$ Global

\section{$\square$ Global}

i. Summary syntheses of current knowledge on associations between FGM/C and HIV, infertility and fistula to inform policy dialogue

ii. Summary synthesis of experiences with social norms theory and measurement 


\section{Study method}

\section{Proposed Countries}

Desk-based multivariate analyses of recent DHS/MICS datasets to expand the global evidence base about the practice of FGM/C.
Egypt, Ethiopia, Kenya, Nigeria, Senegal, Somalia, Sudan 


\section{Study / Method}

\section{Proposed countries}

Mixed method studies that use social network analysis to explain the role of gender norms on continuation of FGM/C in 3 countries with differing strengths of male support for the practice

Qualitative studies to understand and explain the reasons some communities prefer to change the nature of the practice rather than abandon FGM/C $\square$ Egypt, Senegal, Sudan

$\square$ Egypt, Kenya, Nigeria, Sudan, Somalia 


\section{Study / Method}

\section{Proposed countries}

Mixed-method studies explaining

$\square$ Ethiopia, Kenya

how interventions designed to

change social norms through

combined community values

deliberations and public

declarations perform in varying

contexts, the resources required and

their VfM, their likelihood of

effectively ending FGM/C, and their

wider impacts on the lives of girls

and women 


\section{Study / Method}

\section{Proposed countries}

Qualitative studies that explain the causal pathways through which engaging religious leaders can contribute to FGM/C abandonment

Implementation research study that documents and explains how the role of health systems can be strengthened, for prevention and management of FGM/C, through more effective engagement with health professionals $\square$ Ethiopia, Kenya, Sudan

$\square$ Egypt, Kenya, Nigeria, Sudan 


\section{Study / Method}

\section{Proposed countries}

Mixed-method studies that provide key insights into the design and implementation of social marketing campaigns to change social perceptions of uncut girls

Qualitative studies that explain why people do or do not comply with FGM/C legislation to inform future investments in legal instruments for accelerating abandonment
Egypt, Somalia, Sudan

Kenya, Somalia, Sudan 


\section{Study / Method}

\section{Proposed countries}

Case-control study that improve understanding of the impact of FGM/C on female sexuality and inform the improvement of appropriate services for women

Qualitative studies that describe the tensions faced by girls, women and their families who are early or late in the abandonment transition and propose intervention modifications to mitigate these tensions
Egypt, Kenya, Nigeria

Egypt, Nigeria, Sudan 


\section{Study / Method}

\section{Proposed}

\section{countries}

Small-scale, nested studies within the intervention evaluation studies proposed above to determine the extent and nature of wider impacts on girls' and women's lives
- Somalia, Sudan, Egypt, Ethiopia, Kenya 


\section{Continuous process throughout the life of the research programme}

\section{Stakeholder engagement}

\section{Generation of high quality evidence}

\section{Evidence communication}

Capacity building for researchers and stakeholders

\section{Monitoring and evaluation}




\section{Evidence to End FGM/C}

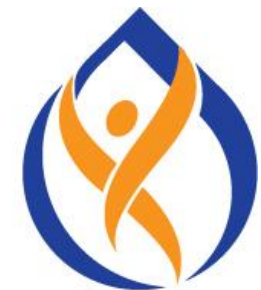

Research to Help Girls and Women Thrive

The Evidence to End FGM/C programme consortium generates evidence to inform and influence investments, policies, and programs for ending female genital mutilation/cutting in different contexts.

Evidence to End FGM/C is led by the Population Council in partnership with the Africa Coordination Centre for Abandonment of Female Genital Mutilation/Cutting (Kenya); Gender and Reproductive Health \& Rights Centre (Sudan); MannionDaniels, Ltd.; Population Reference Bureau; University of California, San Diego; and University of Washington. Evidence to End FGM/C is funded by UK aid by the UK Government.

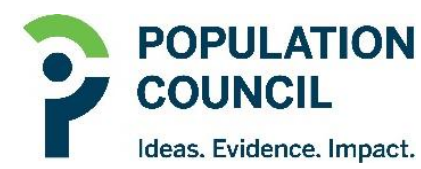

Ideas. Evidence. Impact.
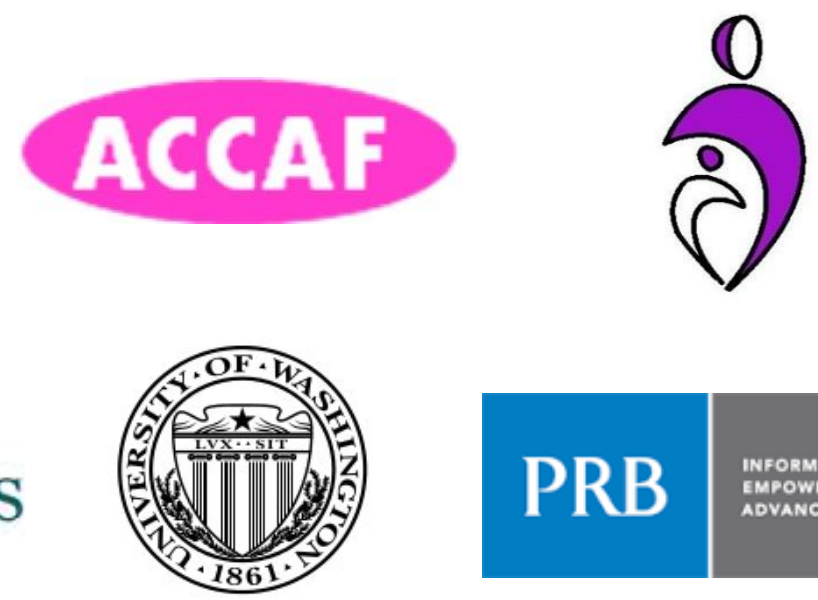

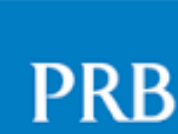

INFORM

EMPOWER

ADVANCE
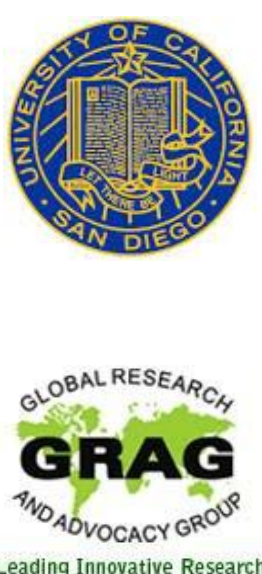

\section{MannionDaniels}




\section{THANK YOU}

